\title{
Effects of Exercise on Oxidative Stress in Rats Induced by Ozone
}

\author{
Catalina Martinez-Campos, ${ }^{1,2,3}$ Eleazar Lara-Padilla, ${ }^{1}$ Rosa Amalia Bobadilla-Lugo, ${ }^{1}$ \\ Robert David Kross, ${ }^{4}$ and Cleva Villanueva ${ }^{1}$ \\ ${ }^{1}$ Seción de Estudios de Posgrado e Investigación, Escuela Superior de Medicina, IPN, Plan de San Luis y Salvador Diaz Mirón S/N, \\ Colonia Casco de Santo Tomás, 11340 México, DF, Mexico \\ ${ }^{2}$ Escuela Médico Militar, Department of Morphology, Boulevard Avila Camacho y Cerrada de Palomas S/N, Colonia Lomas de Sotelo, \\ 11640 México, DF, Mexico \\ ${ }^{3}$ Universidad Pablo de Olavide, Facultad del Deporte, Carretera de Utrera Km 1, Edificio 2, Planta Baja, 41013 Sevilla, Spain \\ ${ }^{4}$ Kross-Link Laboratories, P.O. Box 374, Bellmore, NY 11710, USA
}

Correspondence should be addressed to Cleva Villanueva, villanuevacleva3@gmail.com

Received 30 October 2011; Accepted 22 December 2011

Academic Editor: Narisa Futrakul

Copyright ( 2012 Catalina Martinez-Campos et al. This is an open access article distributed under the Creative Commons Attribution License, which permits unrestricted use, distribution, and reproduction in any medium, provided the original work is properly cited.

\begin{abstract}
Oxidative stress (OS) induced by acute exercise is reduced by chronic exercise. Ozone $\left(\mathrm{O}_{3}\right)$ exposure produces OS. The aim of this study was to determine if aerobic exercise (AE) reduced OS produced by $\mathrm{O}_{3}$. A pilot experiment was performed with male Wistar rats submitted to $\mathrm{AE}$ (trained to swim $90 \mathrm{~min}$ /day). Adaptation to exercise was demonstrated three weeks after training by means of changes in reduced nitrates $\left(\mathrm{NO}_{x}\right)$ in plasma. Therefore, two-week training was chosen for the following experiments. Six of twelve trained rats were exposed to $\mathrm{O}_{3}(0.5 \mathrm{ppm}, 4 \mathrm{~h} /$ day, one hour before exercise). Two groups of sedentary animals $(n=6$ each) were used as controls, one of which was exposed to $\mathrm{O}_{3}$. At the end of the experiments $\mathrm{NO}_{x}, 8$-isoprostane (8-IP), malondialdehyde (MDA), superoxide dismutase (SOD) activity, and carbonyls $(\mathrm{CBs})$ were measured in plasma. CBs did not change in any group. $\mathrm{O}_{3}-$ induced OS was manifested by reduced $\mathrm{NO}_{x}$ and SOD activity, as well as increased 8-IP and MDA. Exercise significantly blocked $\mathrm{O}_{3}$ effects although SOD was also decreased by exercise (a greater drop occurring in the $\mathrm{O}_{3}$ group). It is concluded that AE protects against $\mathrm{OS}$ produced by $\mathrm{O}_{3}$ and the effect is independent of SOD.
\end{abstract}

\section{Introduction}

Oxidative stress (OS) produced by acute exercise is characterized by an excess of free radicals. It was thought that mitochondria were the main source of free radicals in exercise; however, it is now known that even though mitochondria do contribute, other sources are the main contributors (xanthine oxidase, NADPH oxidase, and phospholipase A2) [1-3]. Chronic exercise reduces OS produced by acute exercise $[1,4,5]$. Adaptation to exercise is due, in part, to an increase in the endogenous antioxidant defense $[1,4-7]$. The increase of nitric oxide (NO) availability takes part in the adaptation and the benefits produced by longterm exercise [8-10].

It is thought that the mechanism of adaptation to exercise includes activation of nuclear factor kappa $\mathrm{B}(\mathrm{NF} \kappa \mathrm{B})$ by free radicals, which upregulates the synthesis of endothelial $\mathrm{NO}$ synthase (eNOS) and antioxidant enzymes $[8,9,11,12]$. Long-lasting moderate exercise has benefic effects such as prevention of certain cancers, prolonged lifespan in rodents, reduction of cardiovascular effects of aging and menopause, better metabolic control and renal as well as cardiovascular protection in diabetes, and improvement of chronic heart failure $[3,5-7,11,13-16]$.

Ozone $\left(\mathrm{O}_{3}\right)$ is a common pollutant in urban areas. The effects of $\mathrm{O}_{3}$ extend beyond the lung. $\mathrm{O}_{3}$ exposure produces systemic OS [17]. $\mathrm{O}_{3}$ exposure has been associated with premature mortality [18], cardiovascular mortality [19], myocardial infarction [20], and cerebrovascular diseases [21]. OS and endothelial dysfunction have been related to the cardiovascular toxic effects of $\mathrm{O}_{3}$ [22].

The goal of this study was to determine if moderate aerobic exercise affected $\mathrm{OS}$ produced by $\mathrm{O}_{3}$. 


\section{Material and Methods}

2.1. Animals. Male Wistar rats, 10 weeks old (230-250 g), were supplied by Harlan Mexico. Animals were fed with Purina chow and water ad libitum and submitted to light/dark periods of $12 / 12 \mathrm{~h}$. Animals were kept in a room fed with filtered air to maintain $\mathrm{O}_{3}$ within normal concentrations $(<0.05 \mathrm{ppm})$ according to the USA Environmental Protection Agency (http://www.epa.gov/air/ozonepollution/standards.html). The local Institutional Animal Committee approved all the procedures.

2.2. Training Protocol. Rats were trained to swim $90 \mathrm{~min}$ a day, 7 days a week. Animals swam in water at $35-37^{\circ} \mathrm{C}$, in groups of 6, in a pool measuring $92 \mathrm{~cm}$ long, $42 \mathrm{~cm}$ wide, and $32 \mathrm{~cm}$ deep. Animals were progressively trained during the first week, beginning with 15 min the first day and then increased every day by $15 \mathrm{~min}$ periods to reach $90 \mathrm{~min}$ on the sixth day. After that the animals swam continuously for $90 \mathrm{~min}$ per day. The exercise was performed everyday at noon. After exercise the animals were carefully dried and maintained at room temperature $\left(25^{\circ} \mathrm{C}\right)$.

2.3. Ozone Exposure. $\mathrm{O}_{3}$ exposure was made in groups of six animals in an OTC-1 chamber (In USA, Inc.). The chamber had a servomechanism to maintain $\mathrm{O}_{3}$ concentrations at $0.5 \pm 0.05 \mathrm{ppm}$. The chamber was programmed to destroy $\mathrm{O}_{3}$ in such a way that it was impossible to open the chamber if $\mathrm{O}_{3}$ concentration was above normal ( $\left.\geq 0.05 \mathrm{ppm}\right)$. Animals were exposed to $\mathrm{O}_{3} 4$ hours a day, every day (07:00-11:00 h).

\subsection{Groups. Groups of 6 animals were formed as follows.}

(1) Pilot groups: eight pilot groups were formed in order to analyze adaptation to exercise. Half of those groups were sedentary (kept in their cages, which allowed for free movement) and half were submitted to aerobic exercise, as mentioned above. One, two, four, or eight weeks after training, two groups (sedentary and trained) were anesthetized (sodium pentobarbital $45 \mathrm{mg} / \mathrm{Kg}$, ip). The left carotid was cannulated with a PE50 catheter, and a blood sample $(3 \mathrm{~mL})$ was taken and treated with EDTA. The animals where then sacrificed by anesthesia overdose. Adaptation to exercise was evaluated by measuring reduced nitrates $\left(\mathrm{NO}_{x}\right)$ in plasma using the Griess method (Cayman Chemical Co kit).

(2) With the results of the pilot groups (see below), a two-week period (just before adaptation) was chosen for the following experiments.

(a) Sedentary group. This group remained sedentary and it was kept in the $\mathrm{O}_{3}$ chamber at normal concentrations $(<0.05 \mathrm{ppm})$, for 4 hours a day for 2 weeks, in order to have the same confinement stress as that the rats exposed to $\mathrm{O}_{3}$. (b) Sedentary group exposed to $\mathrm{O}_{3}$ : this group remained sedentary and was exposed to $\mathrm{O}_{3}$ (0.5 ppm, 4 h a day) daily for 2 weeks.

(c) Trained group this group was kept in the $\mathrm{O}_{3}$ chamber at normal concentrations (see group (a)), and one hour later they were trained as explained.

(d) Trained group exposed to $\mathrm{O}_{3}$ this group was exposed to $\mathrm{O}_{3}(0.5,4 \mathrm{~h}$ a day) daily for 2 weeks. One hour after $\mathrm{O}_{3}$ exposure the animals swam as described.

At the end of the two-week experiment, all animals were anesthetized and $5 \mathrm{~mL}$ arterial blood samples were taken. The animals were then sacrificed by anesthesia overdose.

2.5. Oxidative Stress Evaluation. Arterial blood samples were heparinized and centrifuged at $1200 \times \mathrm{g}, 15 \mathrm{~min}$ at $4^{\circ} \mathrm{C}$. Plasma was separated and divided into 5 aliquots of $200 \mu \mathrm{L}$ to measure

(a) reduced nitrates $\left(\mathrm{NO}_{x}\right.$, modified Griess method, Cayman Chemical Co. Kit,)

(b) 8-isoprostane (8-IP, Cayman Chemical Co. ELISA kit),

(c) Malondialdehyde (MDA, Cayman Chemical Co. TBARS kit),

(d) Protein carbonyls (Cayman Chemical Co. kit),

(e) Total activity of superoxide dismutase (SOD, Cayman Chemical Co. kit).

2.6. Statistical Analysis. Data are presented as mean \pm standard error of the mean (SEM) of $n$ experiments. Data were analyzed using the one way ANOVA test and Tukey's multiple comparison test post hoc or the two-way ANOVA test and the Bonferroni test post hoc.

\section{Results}

3.1. Adaptation to Exercise. Results are shown in Figure 1. Adaptation to exercise, measured through $\mathrm{NO}_{x}$ plasma concentration, was reached after two weeks of training. Therefore, a 2-week training was chosen for the experiments where rats were or were not submitted to $\mathrm{O}_{3}$.

3.2. Oxidative Stress Measurement. Protein carbonyls were similar in all the groups (data not shown). $\mathrm{O}_{3}$ exposure significantly decreased $\mathrm{NO}_{x}$ levels $(P<0.05)$ (Figure 2$)$, whereas it increased both 8-IP (Figure 3) and MDA levels (Figure 4) $(P<0.5)$. Exercise prevented those changes although the effect was partial on 8-IP. SOD activity (Figure 5) significantly decreased with $\mathrm{O}_{3}$ and independently with exercise $(P<0.05)$. However, the combination of $\mathrm{O}_{3}$ and exercise resulted significantly increased values of SOD activity. 


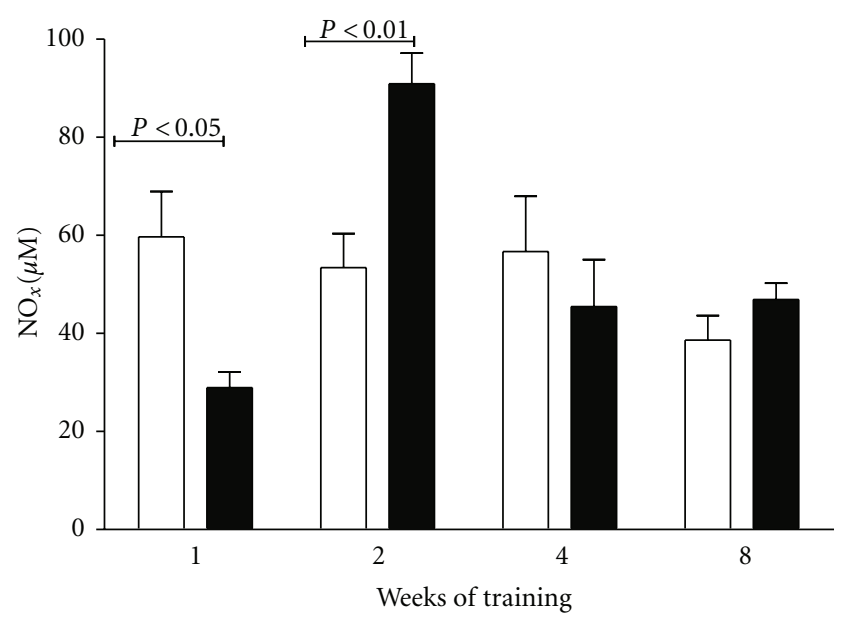

$\square$ No exercise

Exercise

FIgURe 1: Adaptation to exercise. Plasma reduced nitrate $\left(\mathrm{NO}_{x}\right)$ levels decreased significantly one week after training, whereas they significantly increased two weeks after training and returned to normal levels 4 weeks after training (with no changes thereafter). The return to normal is considered adaptation to exercise. Data were analyzed using the two-way ANOVA test and the Bonferroni test post hoc. Data are shown as the mean \pm standard error of mean ( $n=6$ per group).

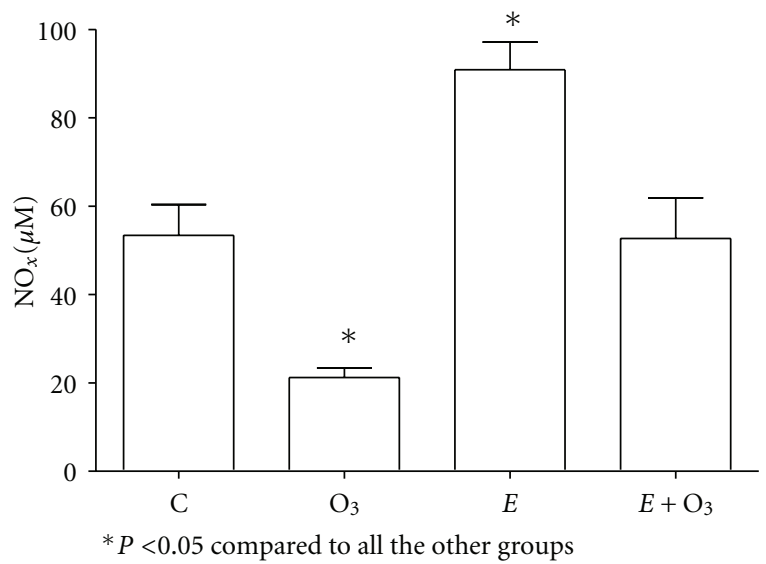

Figure 2: Plasma $\mathrm{NO}_{x}$ concentrations at week two. Ozone $\left(\mathrm{O}_{3}\right)$ exposure $(0.5 \mathrm{ppm} 4$ hours/day) significantly decreased whereas exercise $\left(E, 90 \mathrm{~min}\right.$ per day) significantly increased plasma $\mathrm{NO}_{x}$ concentrations. The effect of $\mathrm{O}_{3}$ exposure was completely blocked by exercise. Data were analyzed using the one-way ANOVA test and Tukey's multiple comparison test post hoc. Data are shown as the mean \pm standard error of mean ( $n=6$ per group).

\section{Discussion}

Acute exercise produces OS mainly through superoxide production $[1,2]$. Chronic exercise reduces OS generated by acute exercise $[1,4,5]$. The mechanism of such adaptation seems to be through activation of $\mathrm{NF} \kappa \mathrm{B}$ by free radicals, which in turn increases the synthesis of antioxidant enzymes and NO synthases $[4,9,12,23]$. Moreover, benefits produced by exercise seem to be given, at least in part, precisely by

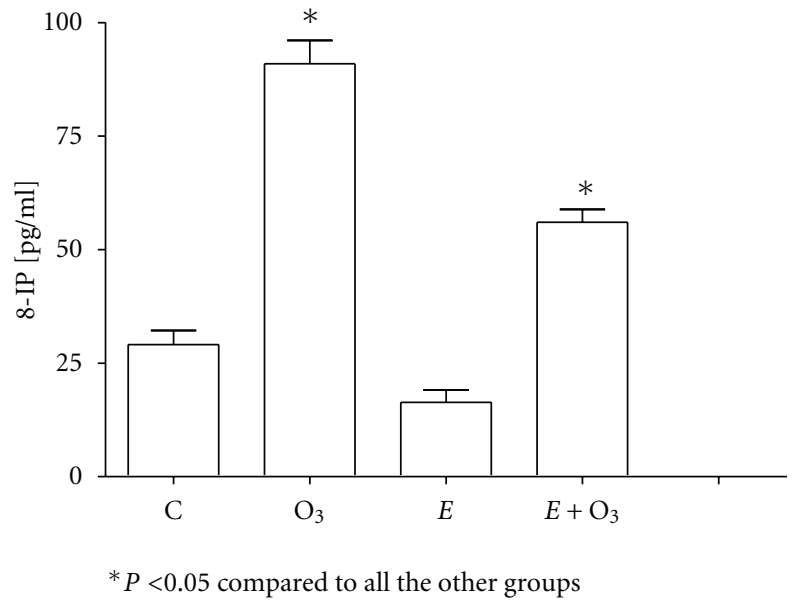

Figure 3: Plasma 8-isoprostane (8-IP) concentrations at week two. Ozone $\left(\mathrm{O}_{3}, 0.5 \mathrm{ppm} 4\right.$ hours/day) exposure significantly increased 8 -IP levels. Even though exercise $(90 \mathrm{~min}$ per day) did not change 8-IP, it partially but significantly blocked the $\mathrm{O}_{3}$ effect. Data were analyzed using the one-way ANOVA test and Tukey's multiple comparison test post hoc. Data are shown as the mean \pm standard error of mean ( $n=6$ per group).

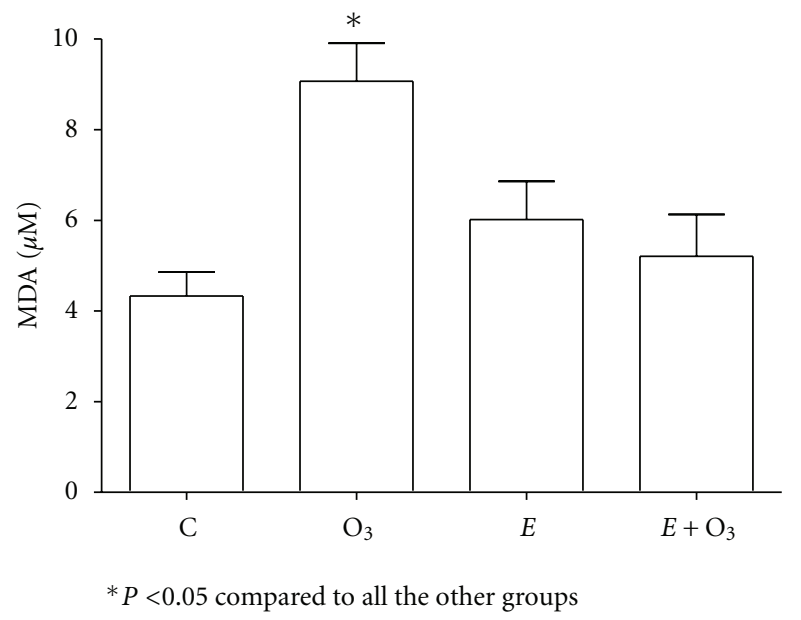

FIgURE 4: Plasma malondialdehyde (MDA) concentrations at week 2. Ozone $\left(\mathrm{O}_{3}, 0.5 \mathrm{ppm} 4\right.$ hours/day) exposure significantly increased MDA levels. Even though exercise ( 90 min per day) did not change MDA, it blocked completely $\mathrm{O}_{3}$ effect. Data were analyzed using the one-way ANOVA test and Tukey's multiple comparison test post hoc. Data are shown as the mean \pm standard error of mean $(n=6$ per group).

the induction of antioxidant enzymes and NO $[1,4,9]$. In the present study adaptation to exercise, evaluated through NO production, was reached after three weeks of training. Adaptation to exercise, measured through other biomarkers, was reported previously in the same period using a similar training model [24].

Since $\mathrm{O}_{3}$ exposure produces OS, we wanted to know if exercise could affect such OS just before adaptation to exercise was reached. Therefore, evaluation of OS in the presence or absence of $\mathrm{O}_{3}$ was made with or without two 


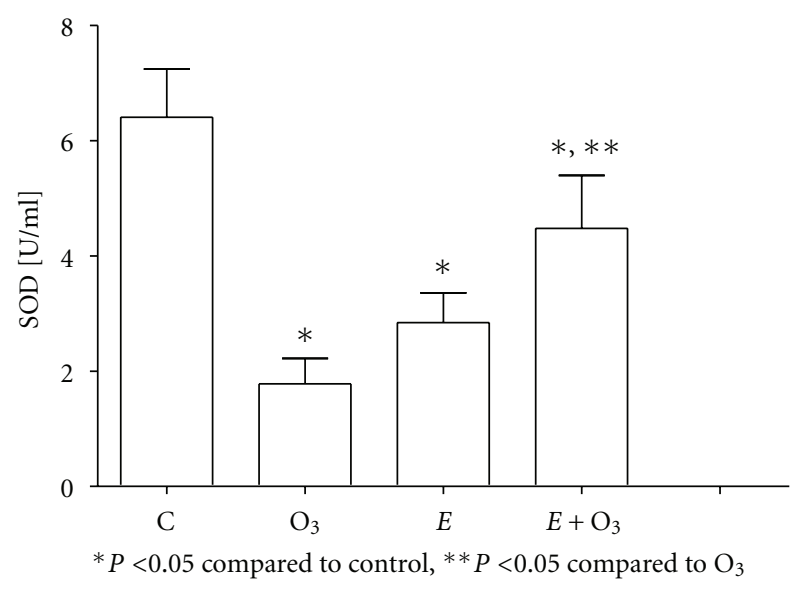

Figure 5: Plasma total superoxide dismutase (SOD) activity at week 2. Ozone $\left(\mathrm{O}_{3}, 0.5 \mathrm{ppm} 4\right.$ hours/day) exposure and exercise ( $E, 90$ min per day) significantly decreased plasma SOD activity. Exercise partially blocked $\mathrm{O}_{3}$ effects. Data were analyzed using the one-way ANOVA test and Tukey's multiple comparison test post hoc. Data are shown as the mean \pm standard error of mean $(n=6$ per group).

weeks of training. We chose a two-week training period because it was the time when $\mathrm{NO}_{x}$ significantly increased, with no changes in concentrations thereafter.

Measurements were made in plasma in order to evaluate the systemic effects of exercise. Other authors report changes produced by exercise in skeletal muscle [24]. However, beneficial effects of exercise are probably systemic. OS produced by $\mathrm{O}_{3}$ was confirmed through the increase of 8-IP and MDA as well as the reduction of $\mathrm{NO}_{x}$ and SOD activity. Decreased production or OS could explain the reduction of NO. NO availability decreases during OS because it is combined with superoxide and transformed in peroxynitrite [25]. 8-IP and MAD were chosen as biomarkers of lipoperoxidation, whereas protein carbonyls were chosen as a biomarker of effects of OS on proteins. SOD was chosen because it is the first-line enzyme dealing with superoxide production.

Interestingly, two-week training protected from lipoperoxidation produced by $\mathrm{O}_{3}$ exposure, At the same time decreased SOD activity but partially blocked $\mathrm{O}_{3}$ effects on this enzyme. It was recently reported that regular exercise prevented premature mortality attributed to pollution in Chinese people older than 65 years [26]. Our findings agree with that paper and suggest that reduction of OS by chronic exercise could have a role in the protection against pollution. It is important to note that our results have the limitation of not being necessarily applicable to exercise in open environments in contact with pollution, because the animals were trained in a pool in a room with filtered air, which would be equivalent to performing indoor exercise. It would be interesting to explore OS when animals are trained in a polluted environment. It is also important to mention that these experiments were conducted with healthy animals. Results could be different in animals suffering from a disease accompanied by OS (e.g., diabetes, hypertension, and hypercholesterolemia).
SOD results are intriguing. $\mathrm{O}_{3}$ exposure, and independent exercise, reduced SOD activity, even though exercise with $\mathrm{O}_{3}$ exposure partially blocked $\mathrm{O}_{3}$ effects. It is known that exercise produces OS and, as a result, the endogenous antioxidant defense is increased. Indeed, it has been reported that exercise increases SOD $[11,15]$. However, this effect has been observed in studies with exercise training longer than 2 weeks. Measurements of the present study were done at the end of the second week of training, just one week before adaptation to exercise. In the present study, the protection of $\mathrm{O}_{3}$ effects produced by exercise (effects on 8-IP, MDA, $\mathrm{NO}_{x}$, and even SOD) could be attributable to changes in other endogenous antioxidants different from SOD (e.g., glutathione peroxidase and catalase).

It is concluded that $\mathrm{AE}$ protects against OS produced by $\mathrm{O}_{3}$, and the effect is independent of SOD.

\section{Acknowledgments}

The CONACYT, Grant no. 083090, supported this work. The study was presented as a poster at the meeting Experimental Biology 2011 in Washington, DC. C. Martinez-Campos is a Ph.D. student at the Universidad Pablo de Olavide, Spain. The authors are grateful for the technical help of Mr. Jorge Campos, who gently trained and took care of the animals.

\section{References}

[1] M. C. Gomez-Cabrera, E. Domenech, and J. Viña, "Moderate exercise is an antioxidant: upregulation of antioxidant genes by training," Free Radical Biology and Medicine, vol. 44, no. 2, pp. 126-131, 2008.

[2] M. J. Jackson, "Free radicals generated by contracting muscle: by-products of metabolism or key regulators of muscle function?" Free Radical Biology and Medicine, vol. 44, no. 2, pp. 132-141, 2008.

[3] M. Ristow and S. Schmeisser, "Extending life span by increasing oxidative stress," Free Radical Biology and Medicine, vol. 51, no. 2, pp. 327-336, 2011.

[4] L. L. Ji, M. C. Gomez-Cabrera, and J. Vina, "Exercise and hormesis: activation of cellular antioxidant signaling pathway," Annals of the New York Academy of Sciences, vol. 1067, no. 1, pp. 425-435, 2006.

[5] A. Boveris and A. Navarro, "Systemic and mitochondrial adaptive responses to moderate exercise in rodents," Free Radical Biology and Medicine, vol. 44, no. 2, pp. 224-229, 2008.

[6] V. Pialoux, A. D. Brown, R. Leigh, C. M. Friedenreich, and M. J. Poulin, "Effect of cardiorespiratory fitness on vascular regulation and oxidative stress in postmenopausal women," Hypertension, vol. 54, no. 5, pp. 1014-1020, 2009.

[7] A. Linke, V. Adams, P. C. Schulze et al., "Antioxidative effects of exercise training in patients with chronic heart failure: increase in radical scavenger enzyme activity in skeletal muscle," Circulation, vol. 111, no. 14, pp. 1763-1770, 2005.

[8] F. P. Leung, L. M. Yung, I. Laher, X. Yao, Z. Y. Chen, and Y. Huang, "Exercise, vascular wall and cardiovascular diseases: an update (part 1)," Sports Medicine, vol. 38, no. 12, pp. 10091024, 2008.

[9] E. Lima-Cabello, M. J. Cuevas, N. Garatachea, M. Baldini, M. Almar, and J. Gonzalez-Gallego, "Eccentric exercise induces 
nitric oxide synthase expression through nuclear factorKB modulation in rat skeletal muscle," Journal of Applied Physiology, vol. 108, no. 3, pp. 575-583, 2010.

[10] Q. J. Zhang, S. L. Mcmillin, J. M. Tanner, M. Palionyte, E. D. Abel, and J. D. Symons, "Endothelial nitric oxide synthase phosphorylation in treadmill-running mice: role of vascular signalling kinases," Journal of Physiology, vol. 587, no. 15, pp. 3911-3920, 2009.

[11] J. M. Lawler, H. B. Kwak, J. H. Kim, and M. H. Suk, "Exercise training inducibility of MnSOD protein expression and activity is retained while reducing prooxidant signaling in the heart of senescent rats," American Journal of Physiology, vol. 296, no. 5, pp. R1496-R1502, 2009.

[12] L. L. Ji, M. C. Gomez-Cabrera, N. Steinhafel, and J. Vina, "Acute exercise activates nuclear factor (NF)- $\kappa \mathrm{B}$ signaling pathway in rat skeletal muscle," The FASEB Journal, vol. 18, no. 13, pp. 1499-1506, 2004.

[13] S. Ghosh, M. Khazaei, F. Moien-Afshari et al., "Moderate exercise attenuates caspase-3 activity, oxidative stress, and inhibits progression of diabetic renal disease in $\mathrm{db} / \mathrm{db}$ mice," American Journal of Physiology, vol. 296, no. 4, pp. F700-F708, 2009.

[14] G. K. McConell, S. J. Bradley, T. J. Stephens, B. J. Canny, B. A. Kingwell, and R. S. Lee-Young, "Skeletal muscle nNOS $\mu$ protein content is increased by exercise training in humans," American Journal of Physiology, vol. 293, no. 2, pp. R821-R828, 2007.

[15] F. Moien-Afshari, S. Ghosh, S. Elmi et al., "Exercise restores coronary vascular function independent of myogenic tone or hyperglycemic status in $\mathrm{db} / \mathrm{db}$ mice," American Journal of Physiology, vol. 295, no. 4, pp. H1470-H1480, 2008.

[16] H.-K. Na and S. Oliynyk, "Effects of physical activity on cancer prevention," Annals of the New York Academy of Sciences, vol. 1229, no. 1, pp. 176-183, 2011.

[17] G. Valacchi, A. Van der Vliet, B. C. Schock et al., "Ozone exposure activates oxidative stress responses in murine skin," Toxicology, vol. 179, no. 1-2, pp. 163-170, 2002.

[18] M. L. Bell, R. D. Peng, and F. Dominici, "The exposureresponse curve for ozone and risk of mortality and the adequacy of current ozone regulations," Environmental Health Perspectives, vol. 114, no. 4, pp. 532-536, 2006.

[19] Y. Zhang, W. Huang, S. J. London et al., "Ozone and daily mortality in Shanghai, China," Environmental Health Perspectives, vol. 114, no. 8, pp. 1227-1232, 2006.

[20] J. B. Ruidavets, M. Cournot, S. Cassadou, M. Giroux, M. Meybeck, and J. Ferrières, "Ozone air pollution is associated with acute myocardial infarction," Circulation, vol. 111, no. 5, pp. 563-569, 2005.

[21] C. C. Chan, K. J. Chuang, L. C. Chien, W. J. Chen, and W. T. Chang, "Urban air pollution and emergency admissions for cerebrovascular diseases in Taipei, Taiwan," European Heart Journal, vol. 27, no. 10, pp. 1238-1244, 2006.

[22] D. J. Sánchez-González, M. A. Moro, C. Castillo-Henkel et al., "Ozone exposure induces iNOS expression and tyrosine nitration in rat aorta," Environmental Toxicology and Pharmacology, vol. 17, no. 1, pp. 1-7, 2004.

[23] L. L. Ji, M. C. Gomez-Cabrera, and J. Vina, "Role of nuclear factor kappaB and mitogen-activated protein kinase signaling in exercise-induced antioxidant enzyme adaptation," Applied Physiology, Nutrition, and Metabolism, vol. 32, no. 5, pp. 930935, 2007.

[24] K. Higashida, S. H. Kim, M. Higuchi, J. O. Holloszy, and D.H. Han, "Normal adaptations to exercise despite protection against oxidative stress," American Journal of Physiology, vol. 301, no. 5, pp. E779-E784, 2011.

[25] R. J. Gryglewski, R. M. Palmer, and S. Moncada, "Superoxide anion is involved in the breakdown of endothelium-derived vascular relaxing factor," Nature, vol. 320, no. 6061, pp. 454456, 1986.

[26] C. M. Wong, C. Q. Ou, T. Q. Thach et al., "Does regular exercise protect against air pollution-associated mortality?" Preventive Medicine, vol. 44, no. 5, pp. 386-392, 2007. 

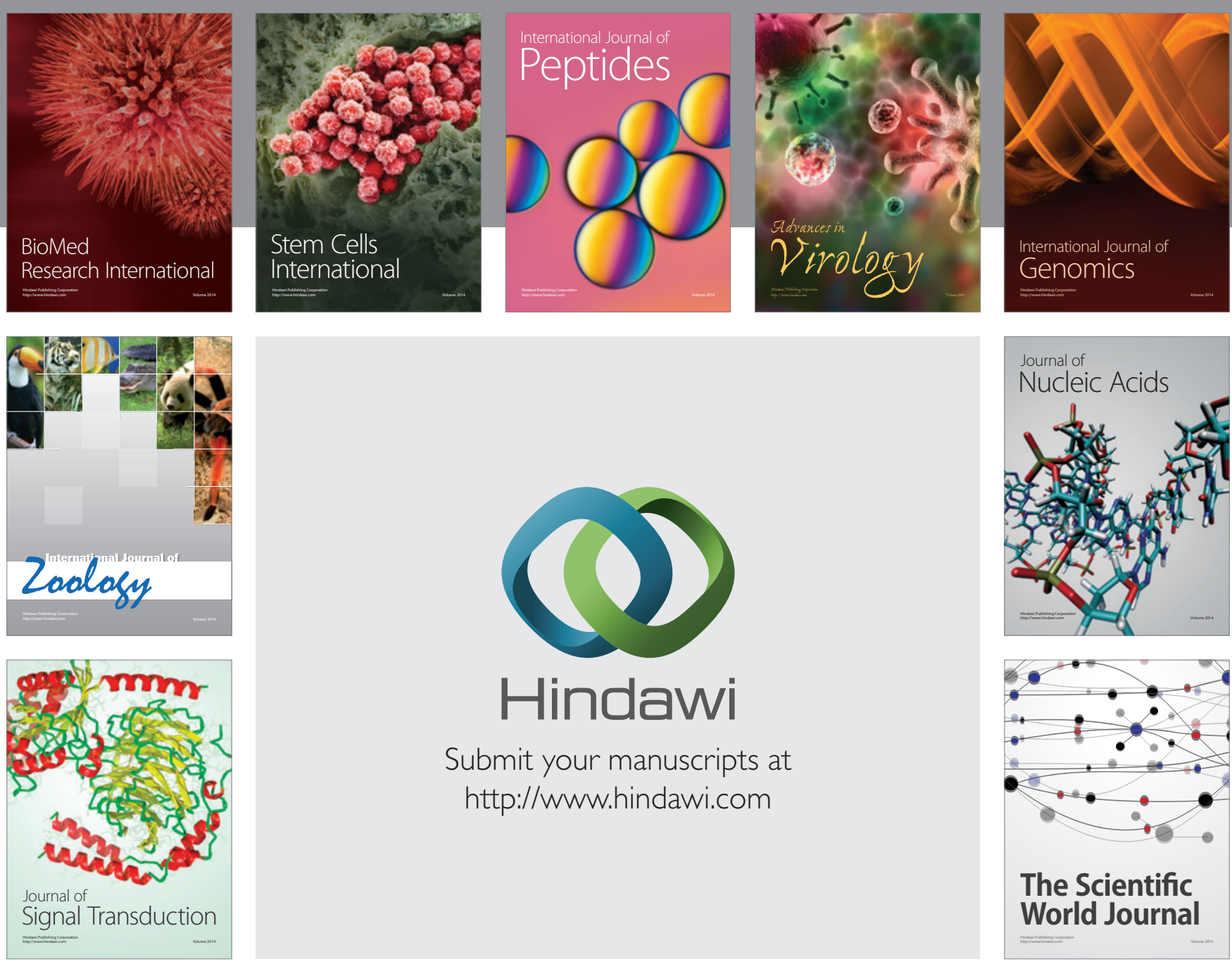

Submit your manuscripts at

http://www.hindawi.com
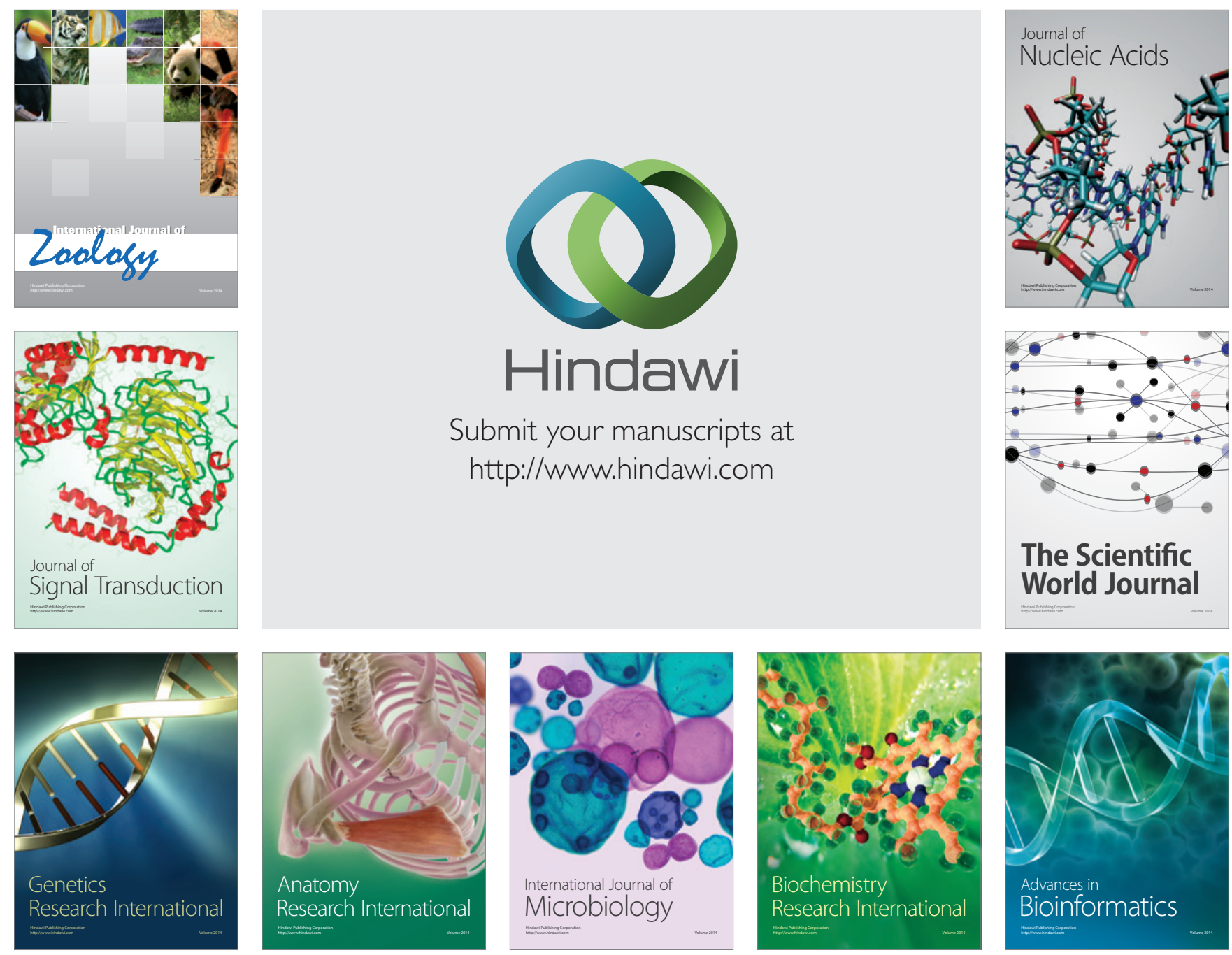

The Scientific World Journal
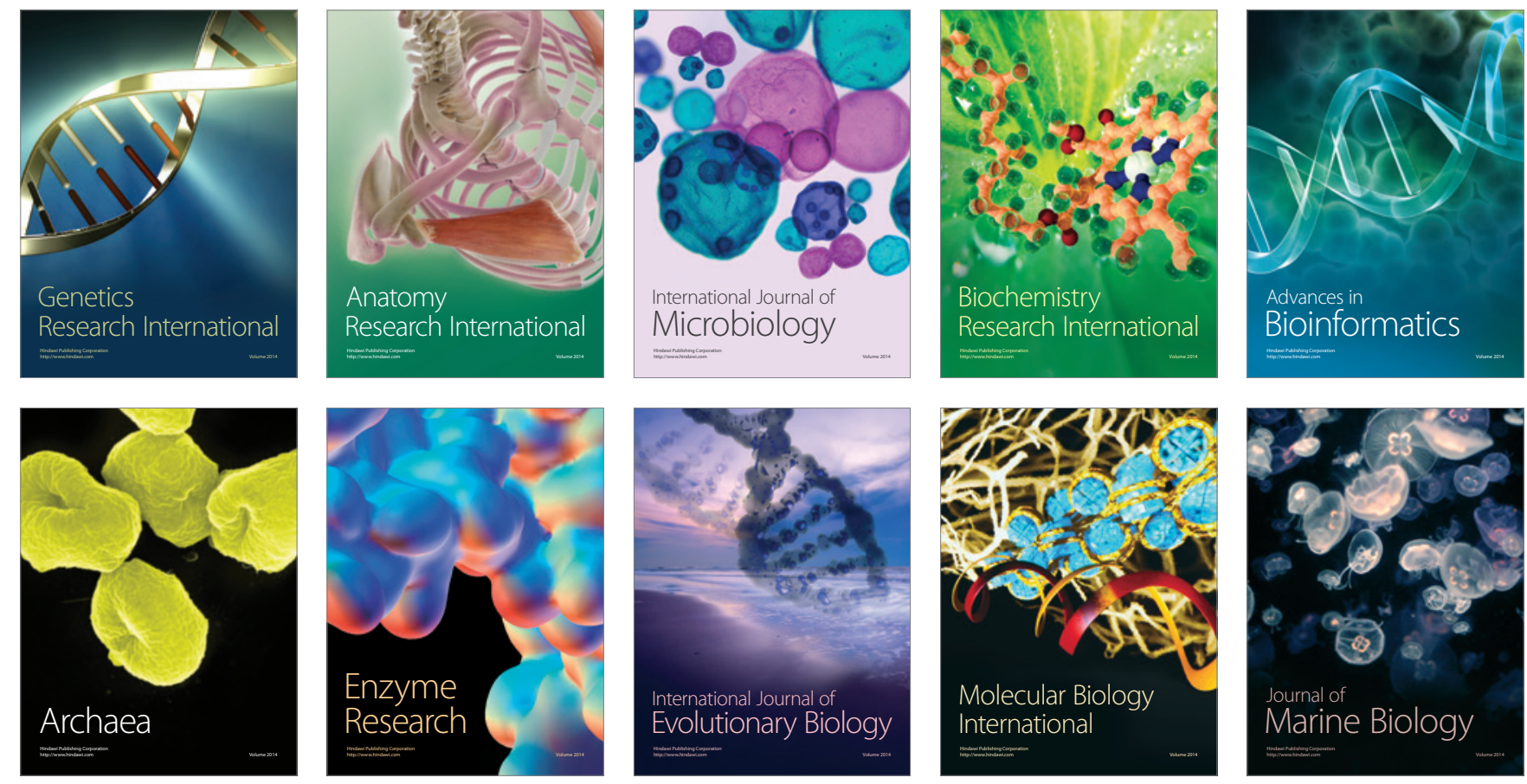